\title{
Impact of Cost Control Techniques on Cost Overruns in Construction Projects
}

\author{
S.N. Malkanthi, A.G.D. Premalal and R.K.P.C.B. Mudalige
}

\begin{abstract}
Construction industry plays an important role in the development of a country. The success of any project will depends on how that project can achieve its objectives in terms of cost, quality and duration. In order to achieve success in a project, it would be essential to plan that project well and have a proper monitoring mechanism in place. Cost overrun is a major problem encountered by many contractors as it makes the profit of a project less secure for the contractor in addition to causing many other problems to all the parties involved. Good cost control techniques would be essential to solve those problems. Thus, it is important to identify cost controlling techniques and their impact on cost overruns. This study was done using a questionnaire survey conducted among C1-C5 grade contractors. The data collected were analysed by converting them into quantitative values using percentage analysis and weighted score analysis. The results indicate the cost controlling practices that are in frequent use and their importance in minimizing the cost overruns in order to reduce over budget and overheads while securing anticipated profits. Finally, it is suggested that CIDA (ICTAD) should encourage contractors to use cost controlling techniques, by conducting training programs, awareness programs, etc. It is also suggested to make the use of some of ICTAD documents mandatory.
\end{abstract}

Keywords: Cost overrun, cost controlling techniques, impact to project budget

\section{Introduction}

Project planning cannot be completed satisfactorily through planning and scheduling only. Project controlling which consists of project monitoring and updating is the other important activity that can be carried out to accommodate the dynamic nature of construction work. Without proper control, even a well-planned and scheduled construction system can cause problems, delays and cost overruns. In general, most (if not all) construction projects experience time delays and cost overruns during their implementation. Cost overruns are considered as one of the most critical issues encountered during the execution of construction projects (Susana, 2012).

Project control includes both progress control and cost control. This research mainly concentrated on cost control. As at present, the construction industry is using different cost control techniques. It is good to have knowledge on the effectiveness of those cost control techniques from the point of view of contractors and how to use those techniques to minimize cost overruns.

The control of project cost is not an easy task as it requires knowledge on the application of cost controlling techniques. Therefore professionals working in the construction industry are required to have theoretical knowledge on cost controlling techniques. The project manager/ planning engineer or any other related professional has to have an understanding on the important aspects of a project such as the selection of an appropriate method of cost controlling, time of applying the technique, etc. Therefore, it will be essential for the construction industry today to use proper project cost controlling. However, the relevant bodies such as ICTAD, Ministry of Housing and Construction etc., have not yet made the required rules and regulations or included appropriate clauses in their conditions of contract to overcome this problem. Thus, this research topic was timely to address the above mentioned problems. Through this research, it was expected to provide an in-depth knowledge on how to follow good monitoring programs and cost controlling techniques in the construction industry.

Given that background, the research objectives of this study were set out to identify the cost

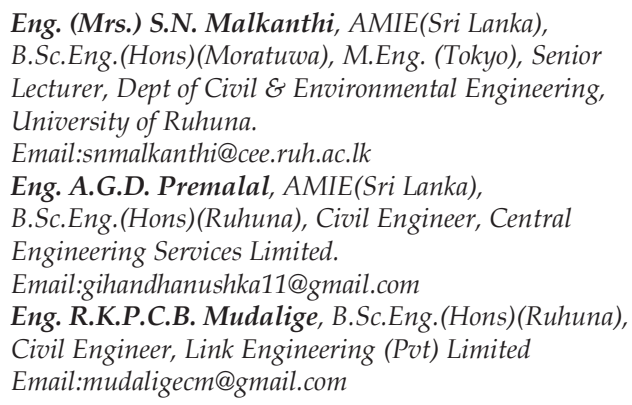


controlling techniques frequently used by contractors in the construction industry and to identify the impact of cost controlling techniques on cost overruns. The research scope was limited to $\mathrm{C} 1-\mathrm{C} 5$ contractors engaged in building projects.

\section{Literature Review}

The three elements or processes involved in cost management; namely cost estimating, cost budgeting and cost controlling (Owens et al., 2006) are shown in Table 1.

Table 1 - Cost management elements

\begin{tabular}{|l|l|}
\hline Element & \multicolumn{1}{c|}{ Description } \\
\hline estimating & $\begin{array}{l}\text { Developing estimates and } \\
\text { measurements for the costs } \\
\text { needed for a resource to } \\
\text { complete the project tasks and } \\
\text { activities. }\end{array}$ \\
\hline Cost & $\begin{array}{l}\text { Collecting the cost estimates, } \\
\text { combining them to develop an } \\
\text { overall cost and baseline. }\end{array}$ \\
\hline Cost & $\begin{array}{l}\text { Managing and controlling } \\
\text { factors that change or affect } \\
\text { the budget. }\end{array}$ \\
\hline
\end{tabular}

Management of construction cost is one of the important tasks for achieving a successful project completion. Unfortunately, it is very seldom that effective cost management could be achieved and often a significant amount of cost overrun has to be experienced (Aris et al., 2013). Thus, the availability of an accurate project estimates and a project budget will be essential if the project is to be delivered within the project budget. That estimation and planning have to be done at the planning stage. By failing to keep an eye on the actual costs while the project is in progress, the completion of the project within the budget will not be possible (Susana, 2012).

However, the poor cost performance of construction projects is a common problem worldwide resulting in a significant amount of cost overruns (Aris et al., 2013). The problem with cost control is not actually the techniques that are used, but rather the poor management of those techniques and the laxity in supervision (ICTAD/CM/01).

'Project Management Book of Knowledge (PMBOK)' has explained some techniques which would be useful for monitoring and controlling construction projects. Some of the advanced techniques mentioned in the PMBOK are earned value management, to-complete index, forecasting, variance analysis, and performance reviews.

Of the above techniques, earn value management is one of the main techniques. The earn value system was firstly used by the Department of Defence of the United States. There are some basic steps as indicated below which have to be followed before applying this theory (Liang, 2005).

- Divide the project into manageable parts of authorized work for which there has to be work breakdown structures (WBSs).

- Define the WBSs in such a way that each activity can be allocated a duration of time and a cost, for its completion.

- Allocate cost and effort to all parts across the entire project-essentially to establish a baseline.

Cost overrun of a project is simply defined as exceeding the budgeted margin of the project. According to Nida \& Azhar, (2008), there are 42 main factors affecting the cost overruns in the construction industry in Pakistan. Price fluctuations of raw materials, modes of financing and payments for completed work, frequent design changes, high cost of machinery, improper planning, high interest rates charged by bankers on loans given to contractors, unstable costs of the manufacturing materials, and the long period between designing \& time of bidding/tendering are some of these factors.

According to ICTAD (CIDA) there have to be several documents to maintain records for controlling the costs incurred to enable their comparison with planned costs. Some of these documents which have been already published by ICTAD are as follows (ICTAD/CM/01): -

- Unit cost sheet

- Weekly statement of direct labour cost

- Weekly statement of machinery hiring cost

- Weekly statement of material cost

- Weekly statement of labour subcontractor's payments

- Monthly statement of overhead costs

- Monthly cost summary

- Weekly statement of output of works (Value of work)

- Contractor's monthly cost control table

- Contractor's monthly cost control chart 
It would be worthwhile to identify from among the above mentioned documents, the documents that need improvements and the new techniques that need to be added to those documents.

\section{Methodology}

This research depended on both qualitative and quantitative information obtained through a questionnaire survey conducted among professionals working at the level of project managers, site managers, etc., in the construction industry.

The questionnaire was developed based on the information gathered during the preliminary survey which was in the form of onsite interviews.

The preliminary questionnaire was prepared using the knowledge gained from the literature review. The preliminary survey was conducted as an open-ended interview based on the preliminary questionnaire. It was useful in fine tuning the final questionnaire and getting the involvement of the professionals working in construction sites.

At present, there are more than 1000 contractors registered with the ICTAD under $\mathrm{C} 1$ to $\mathrm{C} 10$ grades. The research scope was defined to get information only for C1 to C5 grades. Sample size was selected thereafter considering the statistical approaches explained below and it was decided to consider a minimum of 23 contractors.

By using Chi-Squared Distribution

$\mathrm{s}=\mathrm{X}^{2} \times \mathrm{N} \times \mathrm{P} \times(1-\mathrm{P}) \div\left(\mathrm{d}^{2}(\mathrm{~N}-1)+\mathrm{X}^{2} \times \mathrm{P} \times(1-\mathrm{P})\right)$

$\mathrm{s}=$ required sample size

$\mathrm{X}^{2}=$ the table value of chi-square for 1 degree of freedom at the desired confidence level with a value of 3.8415 (using statistical tables)

$\mathrm{N}=$ population size $=512$

$\mathrm{P}=$ population proportion (assumed to be .50 since this would provide the maximum sample size)

$\mathrm{d}=$ degree of accuracy expressed as a proportion of its value $=0.2$

Margin of error $=20 \%$

Confidence interval $=95 \%$

$\mathrm{a}=0.05$ and $\mathrm{V}=1$

Hence,

Required sample size $=$

$\frac{3.8415 \times 512 \times 0.5 \times(1-0.5)}{0.2 \times 0.2 \times(512-1)+3.8415 \times 0.5 \times(1-0.5)}=22.977 \approx 23$

The questionnaires were distributed at the interviews and also sent through Google forms.
The data that were gathered were analysed using Microsoft Excel. Graphs and bar charts were drawn using the information received for each question. Most of the results were presented along with the relevant number of responses received expressed as a percentage of the total number of responses and it was presumed that the most accurate answers were given by those representing the highest percentage.

In some cases, relative index methods were applied to ascertain the importance of the factors concerned. A five-point scale was used to calculate the relative index. (very important-5 points, important- 4 points, fairly important- 3 points, less important-2 points, not important-1 points). By comparing the relative index values obtained for different factors, the most critical factor could be identified.

\section{Results and Discussion}

The survey started by identifying the respondents' backgrounds such as their experiences in terms of years and the number of projects in which they have been involved. It helped to ensure that the data collected were reliable. The research was mainly focussed on finding out the degree of understanding that the contractors had on cost control methods. Figure 1 shows the results obtained which indicate that $67 \%$ of the contractors believe that they have more than $75 \%$ knowledge on cost control systems.

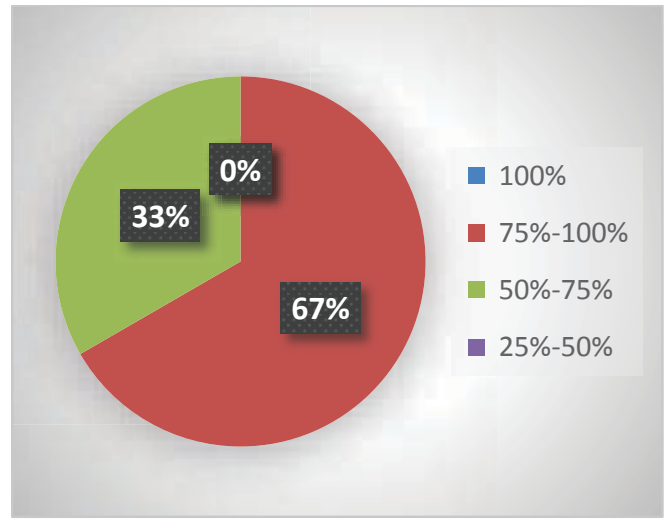

Figure 1 - Contractors' understanding about cost control system

Survey results show that most of the contractors in general are aware of the cost control techniques that are available in the construction industry although their proper use was not much evident. Cost control techniques were identified as a tool for reducing cost overruns. MS Project, earn value management, 
and daily material \& labour controlling are the cost control techniques that were identified as those that are currently being used by the contractors. Figure 2 gives the summary of the cost control techniques that are being presently practiced.

The contractors agreed that MS Project and earn value analysis are the most important techniques available for cost controlling. Although daily material and labour controlling have been used as cost controlling techniques, they are not within the scope of this research. It will be important if this factor can also be incorporated into MS Project software. Contractors who had already adopted these techniques said that ease of monitoring and user friendliness are the factors that most influenced them to use those techniques. Lack of practices and lack of expertise are the main barriers that prevent contractors from using them. The contractors also suggested that ICTAD should conduct regular training programs on these techniques.
The survey focused on the awareness of contractors about the ICTAD guidelines related to cost controlling. The results show that less than $50 \%$ of the contractors are not aware about those guidelines. Most of the contractors, however, believe that important documents which at present are mentioned as ICTAD guidelines should be included in the conditions of contract as a recommendation. Responses received in this regard are shown in Table 2.

Relative Index method was used to identify the critical factors that affect cost overruns. The key factor among them was the shortage of material, labour or mechanical plants which could be overcome by using the above-mentioned ICTAD guidelines. The responses received regarding these problems causing cost overruns are shown in Figure 3.

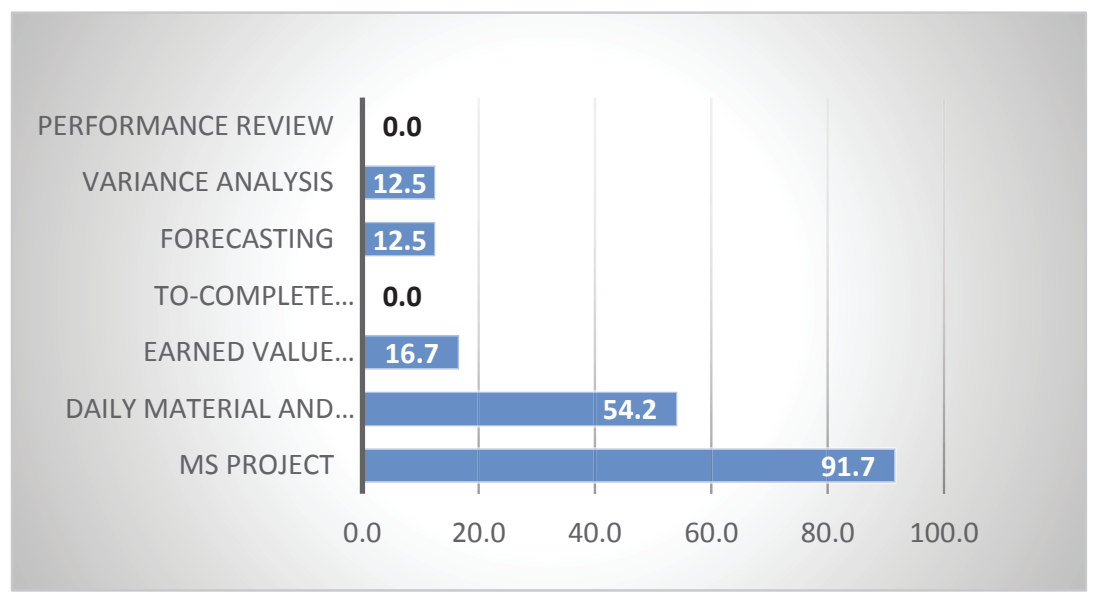

Figure 2 - Current practices of cost control techniques

Table 2 - Documents that contractors prefer to include in the conditions of contract

\begin{tabular}{|l|l|}
\hline Preferred ICTAD(CIDA) documents & Percentage \\
\hline Unit cost sheet & 12.5 \\
\hline Weekly statement of direct labour cost & 41.7 \\
\hline Weekly statements of machinery hire cost & 41.7 \\
\hline Weekly statement of material cost & 33.3 \\
\hline $\begin{array}{l}\text { Weekly statement of labour subcontractor's } \\
\text { payments }\end{array}$ & 33.3 \\
\hline Monthly statement of overhead cost & 16.7 \\
\hline Monthly cost summery & 58.3 \\
\hline $\begin{array}{l}\text { Weekly statement of output of works (Value of } \\
\text { work) }\end{array}$ & 8.3 \\
\hline Contractor's monthly cost control table & 8.3 \\
\hline Contractor's monthly cost control chart & 12.5 \\
\hline
\end{tabular}


Most of the contractors said that their project costs are over budgeted by about 25\% (Figure 4) due to many reasons. Among those reasons, the lack of daily monitoring is found to be second only to material wastage (Figure 5). This indicates that, by using a proper project controlling techniques, over budgeting can be significantly reduced.

\section{Relative Index}

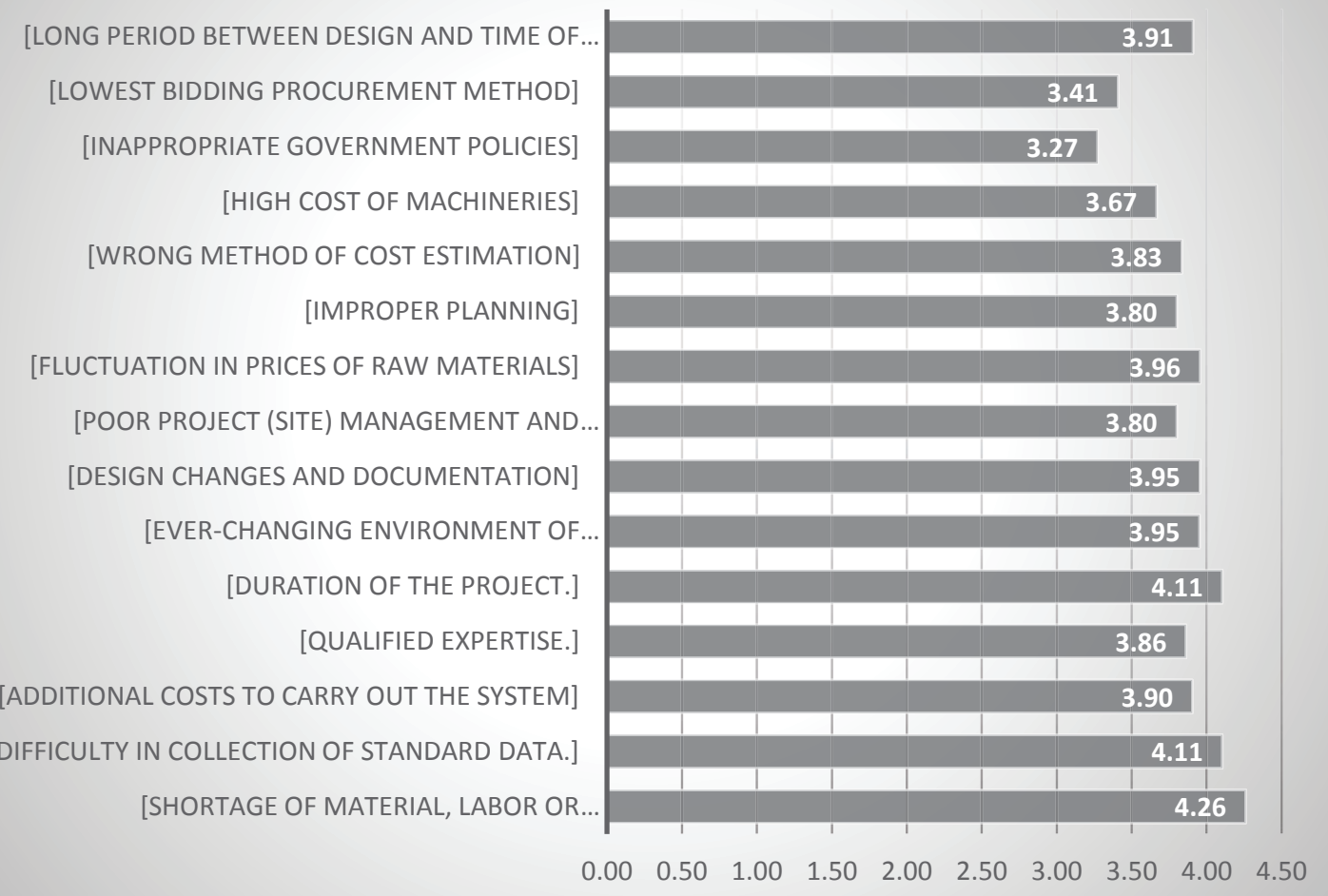

Figure 3 - Problems faced by contractors in controlling the costs on site

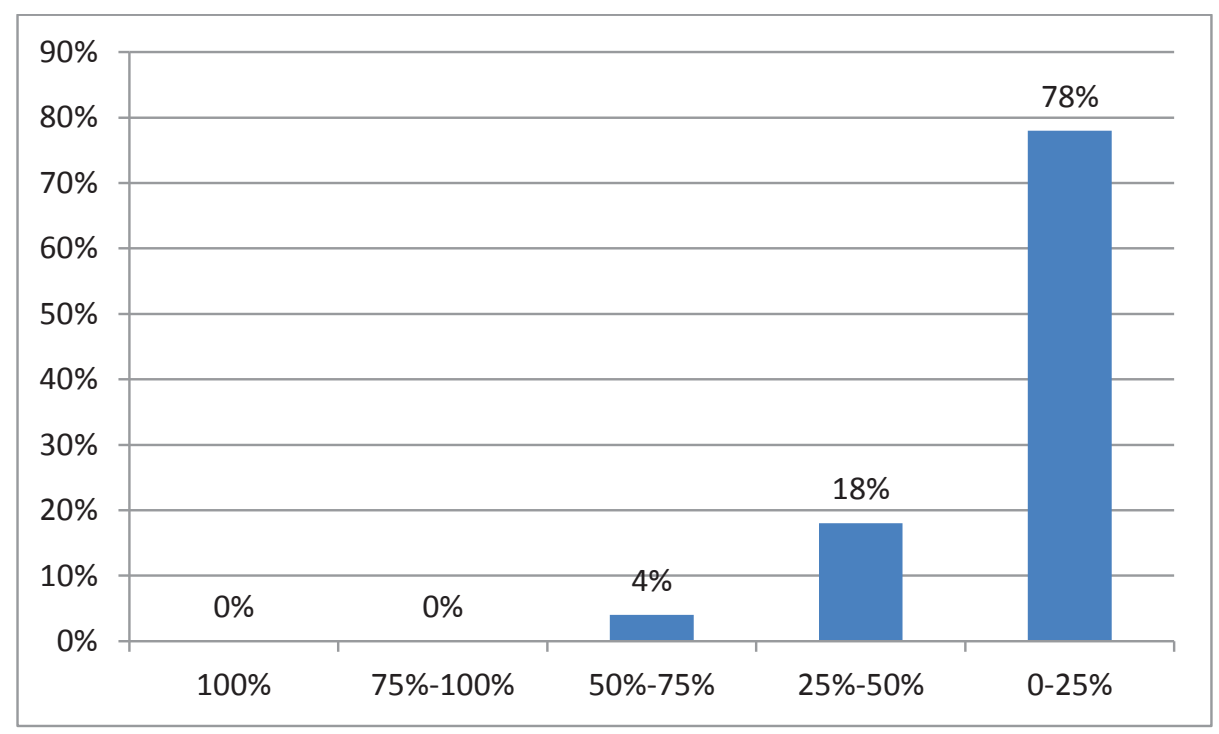

Figure 4 - Over budget percentages 
Corrective measures were identified for over budgeting of projects. Answers received from the respondents were based on their experience in overcoming cost overruns and in the methods suggested to overcome the cost overruns. Most of the contractors suggested the daily monitoring of progress using MS project as the most preferable method (Figure 6).

Many contractors do not use the lessons they learned from their previous projects to ensure the success of their current projects because most of them do not use project management systems. Thus, the past experiences could not be recorded and it appeared that they will start a new project, as a completely new one. However, there were some contractors who used their past lessons to make their current projects successful.

Many contractors tend to include a high-profit margin in the budget. If there is a method to reduce this profit margin, it would be beneficial not only to contractors but also to the client as well. Through this study, the reasons that compel the contractors to increase the profit margin were identified. Those reasons and contractors' responses are shown in Figure 7.

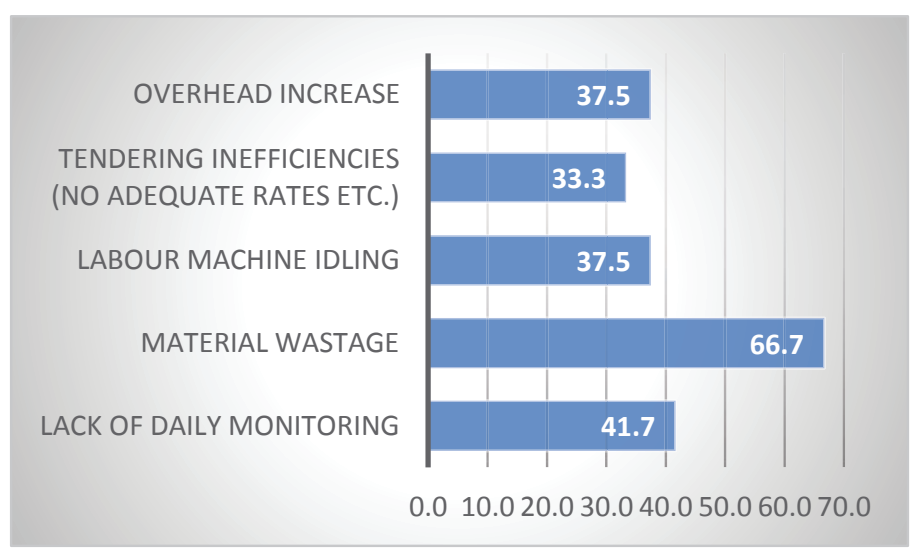

Figure 5 - Reasons for over budgeting

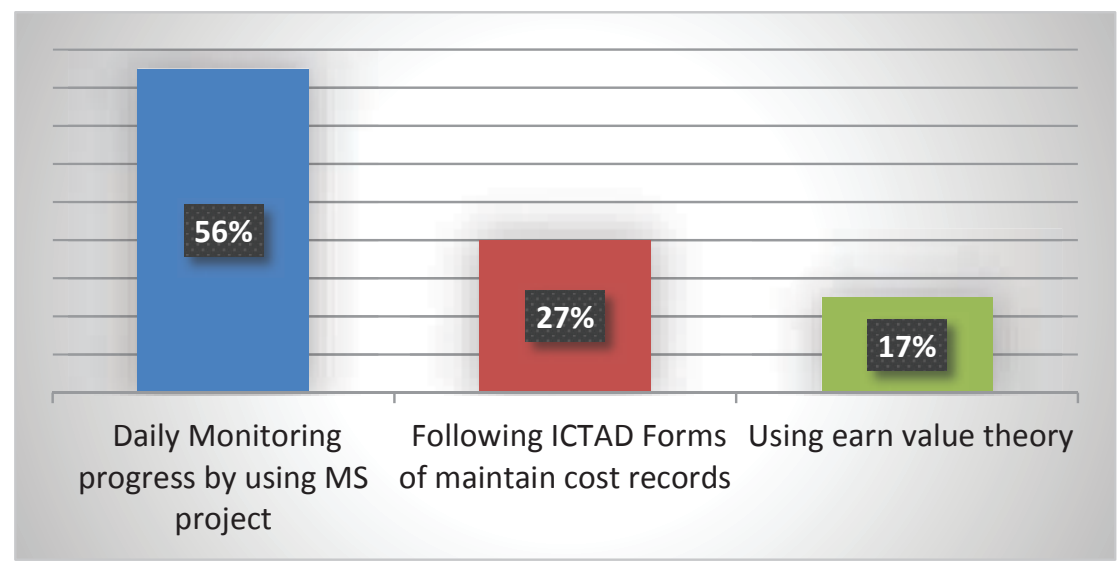

Figure 6 - Corrective measures that can control over budget 


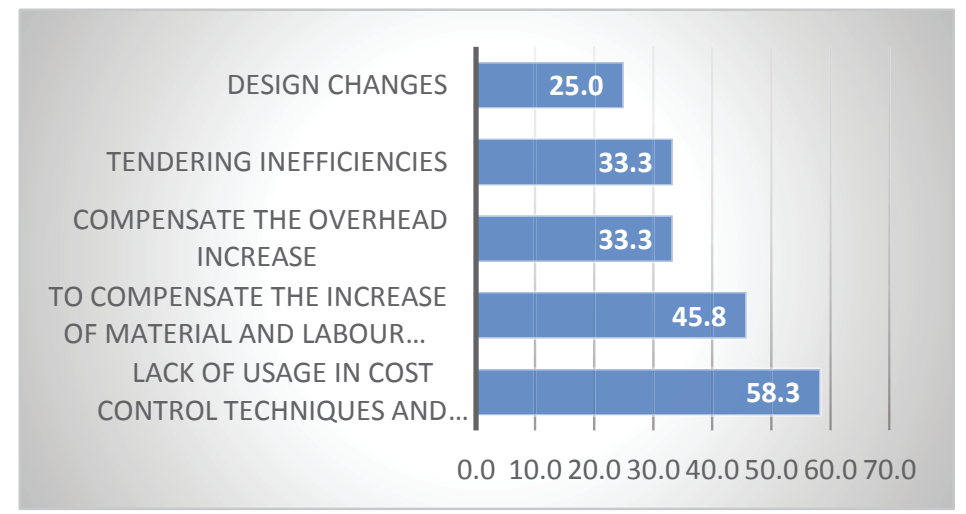

Figure 7 - Reasons for increasing the profit margin

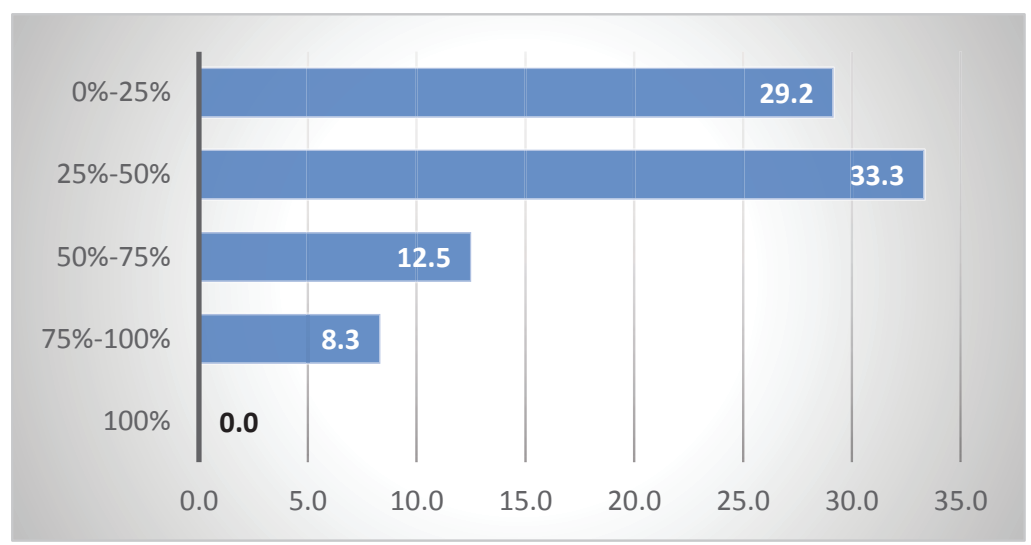

Figure 8 - Percentage overhead reduction due to cost controlling

According to the results shown in Figure 7, lack of cost control techniques and monitoring is the most critical factor will contribute to the increase in the profit margin of a project. Thus, better cost control is essential for reducing the profit margin. Compensation of the increase in the material and labor cost is the next reason for the increase in the profit margin.

As shown in Figure 8, most of the contractors also experienced a reduction in project overheads through the use of cost controlling techniques.

Based on their experience, most of the contractors believe that they can reduce about $50 \%$ of their overhead cost by using proper cost controlling techniques. Some contractors have already achieved more than 50\% overhead reduction through cost controlling techniques. Thus, a proper cost controlling can be considered as an essential component in the construction industry.

\section{Conclusions}

According to the responses received, although there are techniques to minimize cost overruns, the contractors are not inclined to properly implement them due to lack of resources. Even though contractors have been provided with guidelines by ICTAD (CIDA), the majority do not follow them according to the results obtained.

The contractors considered some of the documents made available by ICTAD very important. Hence, the authors would suggest that the documents mentioned below be made compulsory.

- Monthly cost summary sheet.

- Weekly statement of machinery hiring cost sheet.

- Weekly statement of direct labor cost sheet. 
From the survey results, it can be concluded that the following are the most important cost controlling techniques:

- MS Project

- Daily material and labor controlling

- Earn value management

The barriers that impede the implementation of those techniques and the responses of the survey respondents about how those barriers could be overcome have already been explained. The most important solutions suggested by the contractors with regards to the action required by ICTAD (conditions of contract) are summarized below.

- Conduct awareness programs on the importance of MS project and earn value management.

- Provide updates regularly through workshops, seminars, etc.

- Train the responsible professionals.

Further research can be done to validate the conclusions of this research by considering C6 to $\mathrm{C} 10$ contractors and all of projects as well.

The authors believe that by following the guidelines presented in this paper, it would be possible to the contractors to complete their projects successfully by ensuring their anticipated profits.

\section{Acknowledgement}

Authors wish to acknowledge the assistance given by all the professionals working in the construction companies from whom they collected the data for this research.

\section{References}

1. Azis A. A. A., Memon A., Rahman I. A, Karim A.T.A., Controlling Cost Overrun Factors in Construction Projects in Malaysia, Research Journal of Applied Sciences, Engineering and Technology, pp 2621-2629, 2013.

2. George Otim, Fiona Nakacwa, Michael Kyakula, "Cost Control Techniques Used On Building Construction Sites in Uganda" Second International Conference on Advances in Engineering and Technology, pp 267-373, 2011.

3. Guidelines for Effective Construction Management, ICTAD Publication,
4. LIANG, W. K., Cost control in construction project of the site, 2005.

5. Nida \& Azhar, Cost Overrun Factors In Construction Industry of Pakistan. First International Conference on Construction in Developing Countries, Advancing and Integrating Construction Education, Research $\mathcal{E}$ Practice, Karachi, Pakistan, August, 2008.

6. Owens Jason, Scott Burke, Matthew Krynovich \& DJ Mance, Project Cost Control Tools \& Techniques, 2007.

7. Paula, R. \& Alfredo, S., Adding Qualitative Context Factors to Analogy Estimating of Construction Projects, Procedia- Social and Behavioural Science, Vol 74, pp 190-202, 2013.

8. Project Management Body of Knowledge (PMBOK Guide), $5^{\text {th }}$ Edition, Project Management Institute.

9. Susana Gomes Arcila, Avoiding Cost Overruns In Construction Projects In The United Kingdom, Nature, 362(6420), pp 486486, 2012.

ICTAD/CM/01. 